\title{
DEBILITIES AND STRENGTHS OF FEM-BASED CONSTITUTIVE MODELS FOR THE MATERIAL NONLINEAR ANALYSIS OF STEEL FIBER REINFORCED CONCRETE STRUCTURES
}

\author{
JOAQUIM A. O. BARROS \\ ISISE, University of Minho \\ Guimarães, Portugal \\ e-mail: $\underline{\text { barros@ } @ \text { civil.uminho.pt }}$
}

Key words: Finite element method, Constitutive models, Cement based materials, Steel fiber reinforced concrete

\begin{abstract}
During the last decades several improvements have been made on the numerical simulation of concrete type structures by modeling the relevant nonlinearities presented by concrete and reinforcements, as well as their interactions. With the advent of new cement based materials, such is the case of fiber reinforced concrete (FRC), new challenges and difficulties are placed to the computational mechanics community. This work discusses debilities and strengths of constitutive models implemented under the framework of the finite element method (FEM) for the simulation of FRC structures, and points out areas deserving further specific research for more reliable modelling strategies.
\end{abstract}

\section{INTRODUCTION}

Fiber reinforced cement composite (FRCC) is a cement based material reinforced by discrete fibers, whose orientation and distribution in its hardened-state result from a series of stages that FRCC passes, namely [1]: fresh-state properties after mixing; casting conditions into the formwork; flowability characteristics; vibration and wall-effect introduced by the formwork. For percentages of discrete fibers currently used, the post-cracking behavior of FRCC depends significantly on the fiber distribution and orientation [2]. The capability of a numerical model capture, as accurate as possible, the influence of fiber distribution and orientation, as well as the reinforcement mechanisms of fibers crossed by cracks, are the aspects governing its predictive performance. Fiber reinforcement promotes the development of diffuse crack patterns, mainly when matrix strength, and types and contents of fibers are well balanced $[3,4]$. Therefore, smeared crack models (SCM) have been extensively used to simulate the deformational and load carrying capacity of FRCC structures, but several aspects related to the smeared cracking character, and mainly on how to derive the values of the models parameters, arise some difficulties that can compromise the predictive performance of this type of models. These aspects are discussed in the present work in order to demonstrate, not only the potentialities, but also the debilities of these models, in an attempt of promoting further research in the less dominated areas.

All the SCMs discussed in this work are available in the FEMIX V4.0 computer program that was co-founded by the author of the present publication. FEMIX is based on the Finite Element Method (FEM), and includes a large library of types of finite elements (FE), which is complemented with a set of point, line 
and surface springs that model diverse contact conditions with the supports, and also several types of interface FE to model inter-element contact. Embedded line FE can be added to other types of elements to model reinforcement bars. Special embedded FE can be used for simulating fibers in FRCC context. All these types of FE can be simultaneously included in the same analysis, with the exception of some incompatible combinations. The analysis may be static or dynamic, and the material behavior may be linear or nonlinear. Data input is facilitated by the possibility of importing CAD models. Post-processing is performed with a general purpose scientific visualization program named drawmesh, or using GID. In the same analysis several nonlinear models may be simultaneously considered.

Interface FE with appropriate friction laws and nonlinear springs may also be simultaneously considered. Time dependent phenomena like concrete maturation including creep and shrinkage can be also simulated. The global response history is recorded in all the sampling points (SPs) for post-processing purposes. Advanced numerical techniques are available, such as the Newton-Raphson method combined with arc-length techniques and path dependent or independent algorithms. When the size of the systems of linear equations is very large, a preconditioned conjugate gradient method can be advantageously used [5].

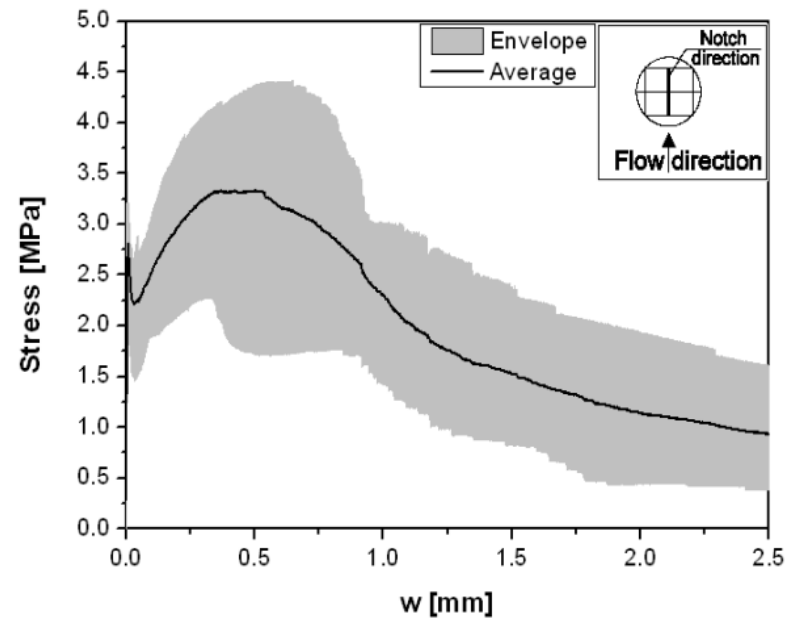

(a)

\section{DEBILITIES AND STRENGTHS OF SMEARED CRACK MODELS}

\subsection{Evaluation of model parameters}

As already indicated, SCMs, mainly the multidirectional fixed smeared crack model (MSCM), have been used to simulate the deformational and load carrying capacity of FRCC structures, but the accuracy of these models for predicting the crack width and crack spacing is quite limited [6-8]. Crack in these models must be regarded as smeared cracks distributed in the material representative of the SP. These models require the knowledge of the fracture mode I parameters, and for FRCC structures failing in shear it is also relevant the characterization of the fracture modes II and III, this last one in the case of using solid FE $[9,10]$. However, the data defining the fracture modes depends significantly of the adopted test setup, type of specimen, and stress field introduced by the applied loading, due to the influene of fiber distribution and orientation [11,12]. Therefore, the stress crack width relationship $(\sigma-\mathrm{w})$, which defines the fracture mode I parameters (stress at crack initiation, $f_{c t}$, mode I fracture energy, $G_{f I}$, and shape of the $\sigma-w)$, depends significantly on the orientation of the applied load regarding the notched plane of the specimen where crack is forced to initiate and propagate. Figure 1 shows how $\sigma$-w can be different when the tensile load applied to the notched plane has distinct orientation regarding the flow direction of the FRCC [2].

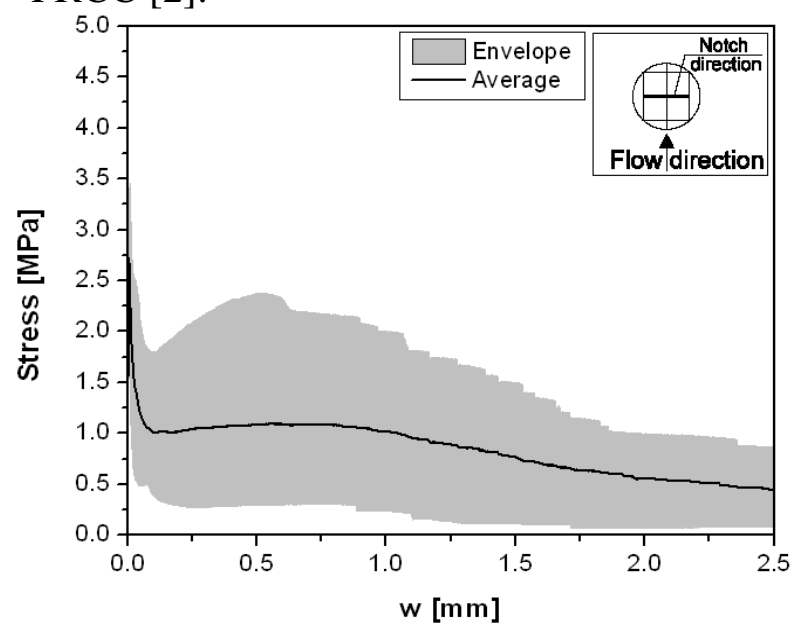

(b)

Figure 1: Uniaxial tensile stress-crack width relationship, $\sigma$-w: (a) $\theta=0^{\circ}$; (b) $\theta=90^{\circ}$ [2]. 
This is mainly pronounced when stiff fibers are used, like steel fibers, since they have the tendency of lining up perpendicularly to the radial flow due to the uniform flow profile velocity that diffuses outwards radially from the casting point, mainly when FRCC has a selfcompacting character (Figure 2).

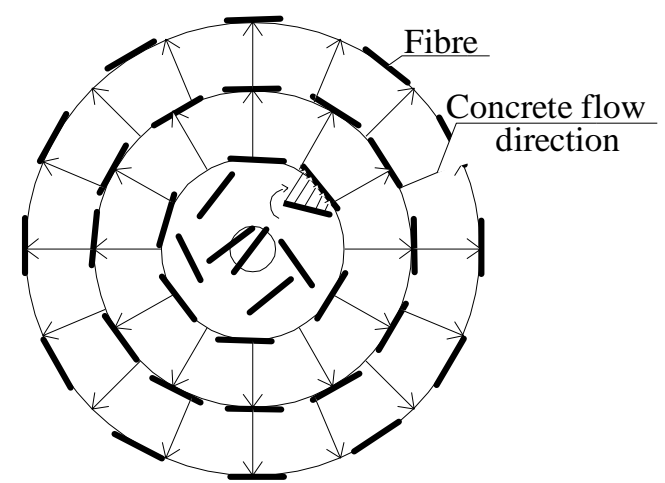

Figure 2: Explanation for fiber alignment in flowing concrete of a panel casting from its center [2].

The inverse analysis (IA) is another alternative methodology used to derive the $\sigma-\mathrm{w}$ [13-15]. In this case, simpler experimental tests than uniaxial tensile test can be performed, such is the case of three point notched beam bending test, 3PBBT [16]. The $\sigma-\mathrm{w}$ is derived by fitting the force-deflection or the force versus crack mouth opening displacement (CMOD) as much as possible by a FEM based approach that assumes the propagation of a unique planar crack along the notched plane, see Figure 3. A modification of the indirect tensile test,

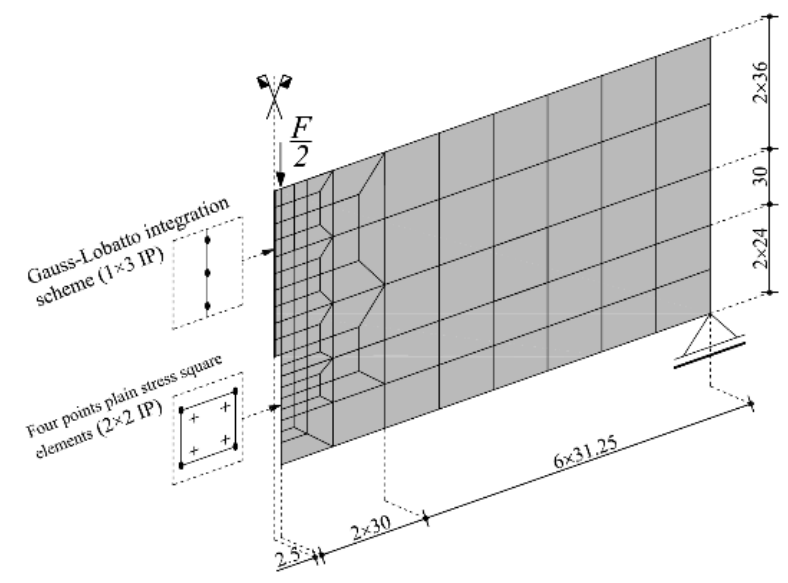

(a)
Brazilian test, [13,14], and the double edge wedge splitting test, DEWST, [18], have also been adopted for this purpose.

However, in experimental 3PBBT, even with relatively small content of fibers, more than one non-planar cracks are formed. Therefore, attributing the energy consumed in this fracture process to the formation of this unique planar crack conducts to an upper estimation of the fracture energy. This leads to unsafe predictions of the load carrying capacity at serviceability and ultimate limit states, as demonstrated in the example of Figure 4, where the curve FEM (IA) represents the simulation of a $1 / 4$ scale prototype of a residential/commercial building constituted by an elevated steel fiber reinforced self-compacting concrete (E-SFRSCC) slab, whose fracture mode I parameters were determined by IA based on the results obtained in 3PBBT, Figure 3 [19]. Further inaccuracies are introduced if the fiber distribution and orientation in the 3PBBT adopted to derive the fracture mode I parameters are not representative of the real slab conditions. Inverse analysis with DEWSTs performed in specimens representative of the fiber distribution and orientation can provide $\sigma$-w diagrams better simulating the FRCC applied in the structure and, consequently, more reliable predictions of the behavior of FRCC structures can be obtained.

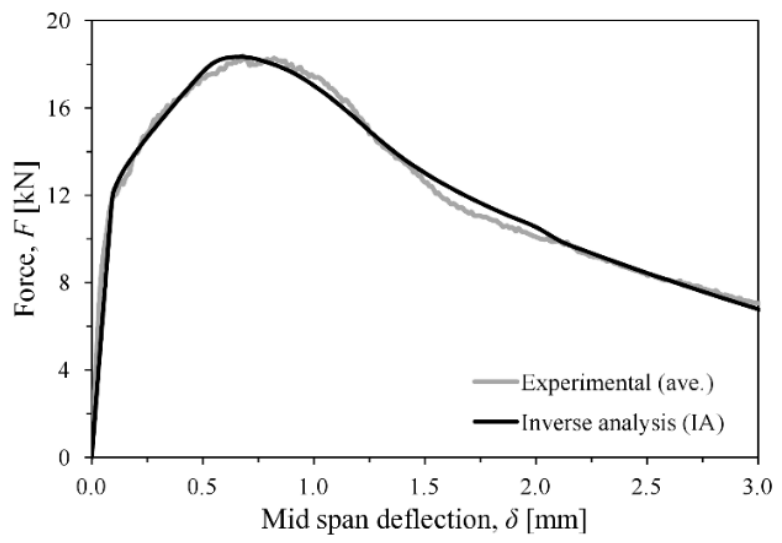

(b)

Figure 3: Inverse analysis to determine the fracture I parameters of FRCC by using data derived from 3PBBTs: (a) typical finite element mesh (dimensions in $\mathrm{mm}$ ); (b) experimental vs numerical results [19]. 


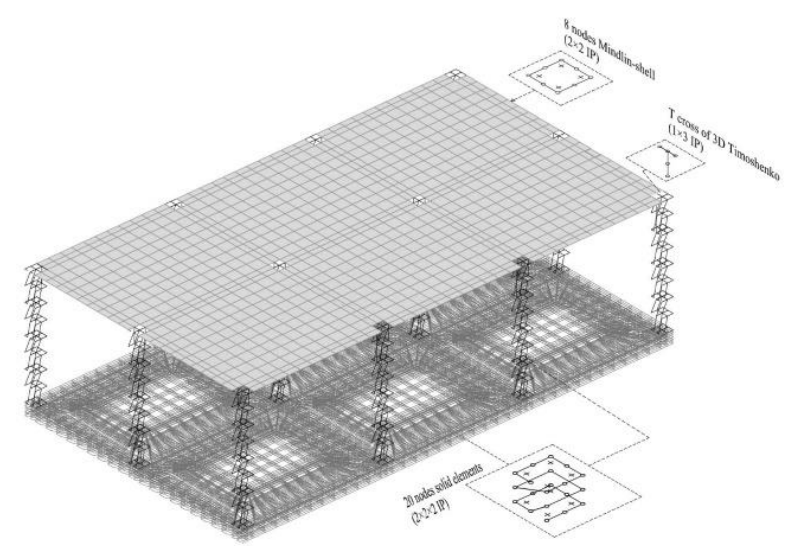

(a)

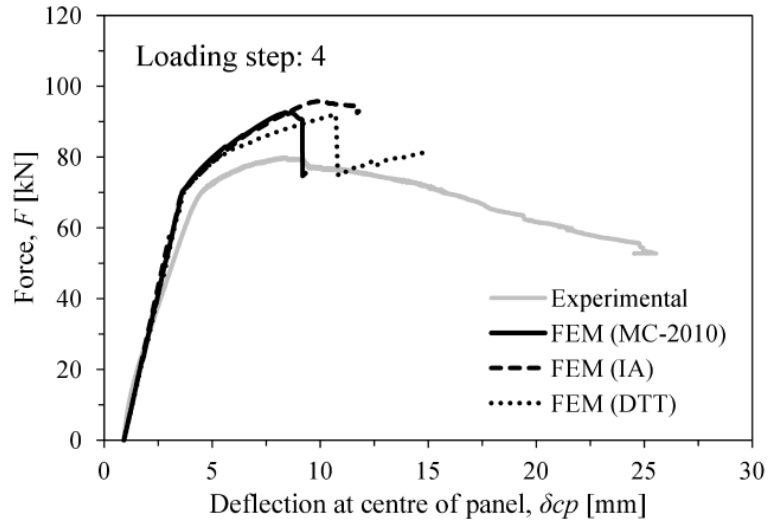

(b)

Figure 4: (a) 1/4 scale building prototype with E-SFRSCC slabs; (b) influence of the fracture mode I parameters on the modeling accuracy [19].

When using steel fibers and powerful vibration conditions during casting of SFRC, fibers tend to sink, since they are the concrete constituent of higher mass density, slenderness, and stiffness. To capture this effect in slab and shell type structures, the structure should be decomposed in layers, and the fracture properties to the FRCC of each layer must be representative of the fiber distribution and

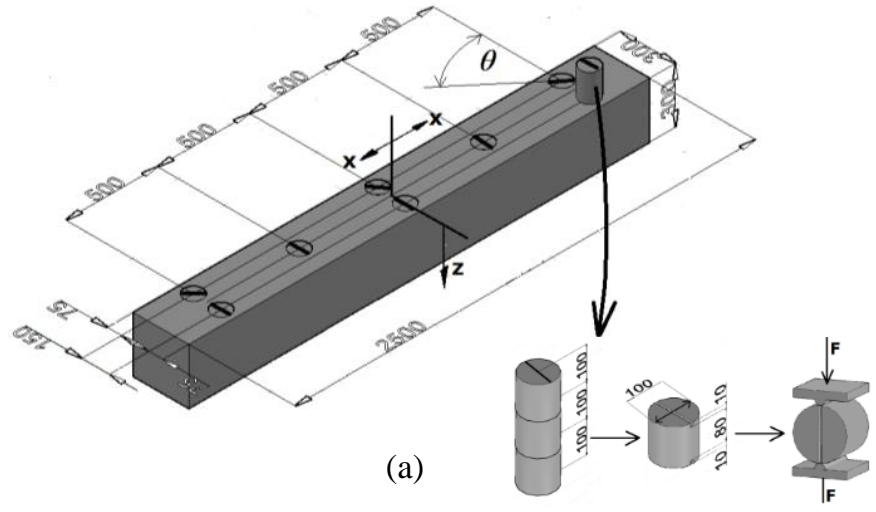

Figure 5: (a) Extraction of specimens for the DEWSTs (dimensions in mm); (b) a view of DEWST.

\subsection{Modelling the fracture process in the scope of SCMs}

The influence of the fiber orientation and distribution on the fracture mode I parameters claims for the adoption of tools capable of simulating the fiber orientation and distribution, using probabilistic approaches and regarding fibers as 3D- truss or beam FE [21], but modeling the complex fiber reinforcement mechanisms is still a challenging task.

Another alternative is the adoption of $\sigma-\mathrm{w}$ responses whose characteristics depend on the (b)

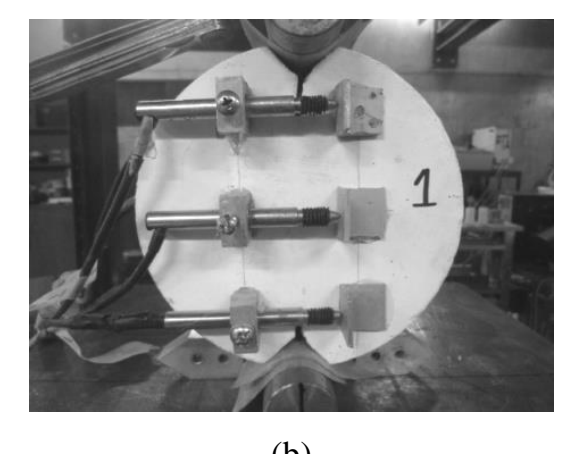

orientation at the level of the layer [20]. For this purpose, DEWST performed with round slices sawn from cylinder cores extracted from a FRCC volume representative of the technological conditions of the real applications is a recommended strategy to derive the fracture mode I parameters of FRCC that assures reliable modelling predictions, Figure 5. 
the formation of another crack in MSCMs. A current criterion available in this type of models allows the formation of a new crack when the maximum principal tensile stress $\left(\sigma_{t l}\right)$ attains the actual tensile strength of the material representative of the $\mathrm{SP}\left(\sigma_{n, 1}^{c r}\right)$ at less than a certain tolerance $\left(\left|\sigma_{t l}-\sigma_{n, 1}^{c r}\right| \leq\right.$ Toler_ $\left.\sigma\right)$ and the angle between the new and already existing cracks $\left(\theta_{\text {new }}^{c r}\right)$ is higher than an assumed threshold angle $\left(\theta_{\text {new }}^{c r}>\theta_{t h}\right)$. The numerical simulations demonstrate the stiffness and load carrying capacity after crack initiation of a RC structure decrease with the decrease of $\theta_{t h}$, being the rotating crack model the extreme example of this situation $[22,23]$, since cracking is rotating continuously in order to maintain principal strains and stresses coaxial. Therefore, a scientific base decision is needed for the definition of $\theta_{t h}$. Furthermore, the fracture parameters to be attributed to a new crack in an already cracked SP is a subject not yet addressed in a comprehensive way, due to the complexity of mutual interactions when non-orthogonal cracks exist in the same material region. The majority of the SCMs assume no mutual interaction between crack opening and crack sliding, but experimental tests in this specific aspects evidence that the crack normal stress depends not only on the crack opening, but also on the crack sliding, while crack shear stress depends not only on the sliding but also on the crack opening [24]. Experimental research has also demonstrated that this dependence is path dependent [25]. However, to maintain the stiffness matrix of the structure symmetric, with consequent benefits in terms of computer memory storage and computing time, mainly when the models are applied to large scale structures, an independence of the fracture modes is generally assumed. The most common dependence of crack shear stress transfer on the fracture mode I parameters is the adoption of a shear retention factor $(\beta)$ that affects the transverse elasticity modulus of FRCC, with a unitary value at the crack initiation, and decreases with the crack normal strain according to a function that would take into account the aggregate interlock, and the reinforcement crossing the crack [23]. However, even adopting this type of function for defining $\beta$ in a smeared incremental approach, a stiffer and higher load carrying capacity are predicted for elements failing in shear [26], and the crack patterns registered experimentally are also not well captured numerically. In a constitutive model based on an incremental approach, the increment of the crack shear stress, $\Delta \tau_{n t}^{c r}$, is only null when the crack normal strain exceeds the ultimate crack normal strain, $\varepsilon_{n}^{c r} \geq \varepsilon_{n, u}^{c r}$, i.e. $\beta$ becomes null. Therefore, even if the crack opening is increasing, the crack shear stress, $\tau_{t t}^{c r}$, can also increase up to an asymptotic value, regardless the crack is no longer capable of transferring normal tensile stresses (Figure 6), which is unrealistic.

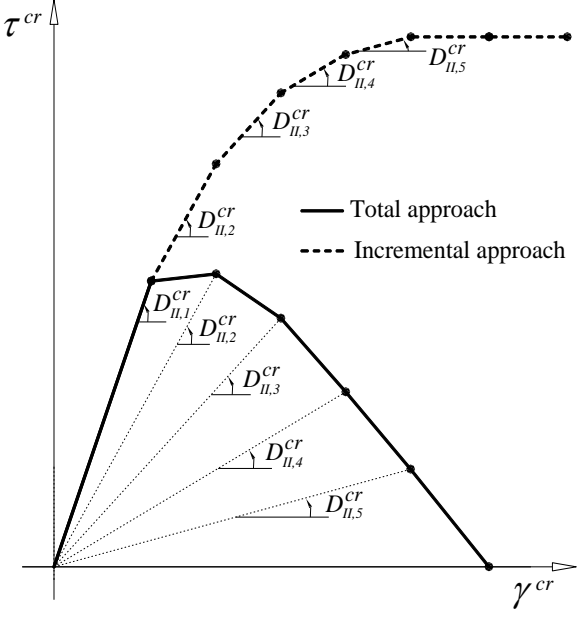

Figure 6: Relation between crack shear stress and crack shear strain for the incremental and total approaches.

This occurrence can activate the criterion for opening a new crack $\left(\left|\sigma_{t I}-\sigma_{n, 1}^{c r}\right| \leq\right.$ Toler_ $\sigma$ and $\left.\theta_{\text {new }}^{c r}>\theta_{\text {th }}\right)$, which besides predicting uncharacteristic crack patterns, the occurrence of several cracks at a SP introduces difficulties in accomplishing the correct current constitutive laws of the formed cracks, even adopting a rigorous strain-decomposition procedure [27]. In an attempt of overcoming these deficiencies, a total approach for the crack shear stress-shear strain relationship has been used [28], where $\tau_{n t}^{c r}$ decreases with the increase of the crack shear deformation $\left(\gamma_{n t}^{c r}\right)$, as is expected when $\varepsilon_{n}^{c r}$ is also increasing (Figure 6). 
However, the enhancement of the predictive performance assured by the total versus the incremental approach for elements failing in shear has been relatively limited [29]. To simulate the decrease of crack shear stress transfer during the evolution of the fracture process, $\tau_{n t}^{c r}-\gamma_{n t}^{c r}$ relationships that include a softening branch, Figure 7, have been demonstrated capable of simulating accurately the deformational response of structures failing in shear, Figure 8 [26].

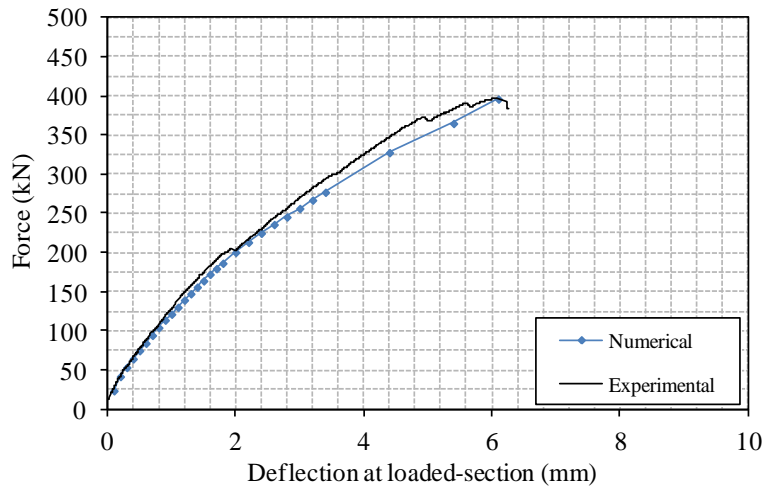

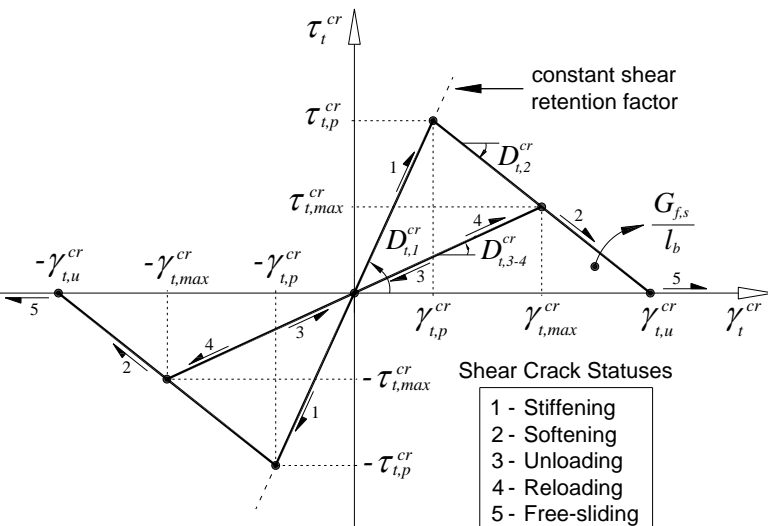

Figure 7: Diagrams to simulate the crack shear stress $v s$ crack shear strain [26].

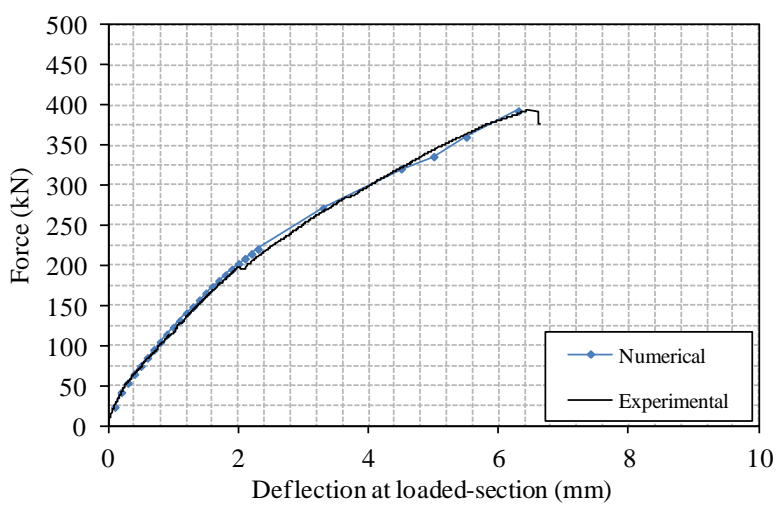

Figure 8: Predictive performance of a MSCM with a linear $\tau_{n t}^{c r} \gamma_{n t}^{c r}$ shear softening diagram (two examples) [26].

However, the predictive performance of this approach depends significantly on the values adopted for the parameters that define the $\tau_{n t}^{c r}$ $\gamma_{n t}^{c r}$ diagram, namely the crack shear strength, $\tau_{t, p}^{c r}$, the shear fracture energy, $G_{f, s}$, and the $\beta$ parameter that defines the first branch of $\tau_{n t}^{c r}-\gamma_{n t}^{c r}$ , as is evidenced in Figure 9. The influence of these parameters is quite significant, mainly the

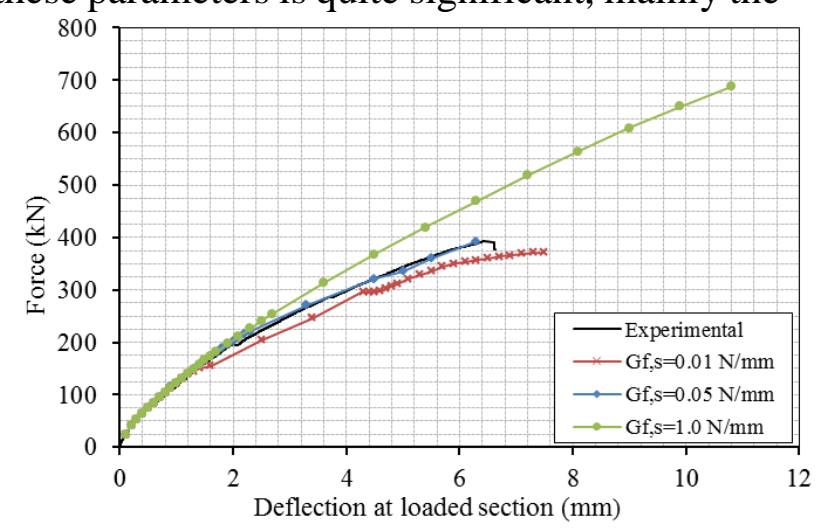

(a)
$G_{f, s}$ and $\tau_{t, p}^{c r}$, and a critical aspect is the difficulty of obtaining experimentally these parameters. Some attempts have been made for the evaluation of these parameters for SFRC [30], but pure shear stress field is quite difficult to materialize experimentally, therefore, IA procedure is being used for this purpose [31].

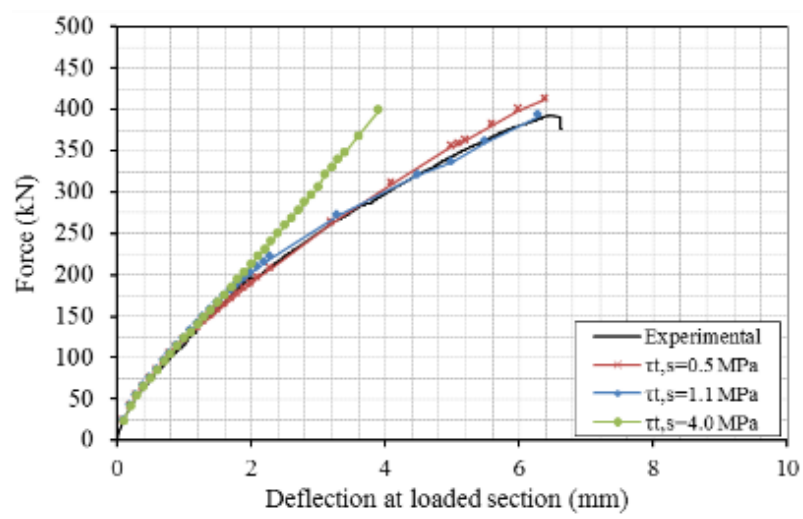

(b)

Figure 9: Influence on the force $v s$ deflection response of RC failing in shear of the: (a) $G_{f, s}$; (b) $\tau_{t, p}^{c r}$ [26]. 
Similar approach was also used to simulate the out-of-plane shear components of structures failing in punching and modelled by MindlinReissner shell theory [32]. Figure 10 demonstrates that a diagram similar to the one represented in Figure 7 for simulating both out-

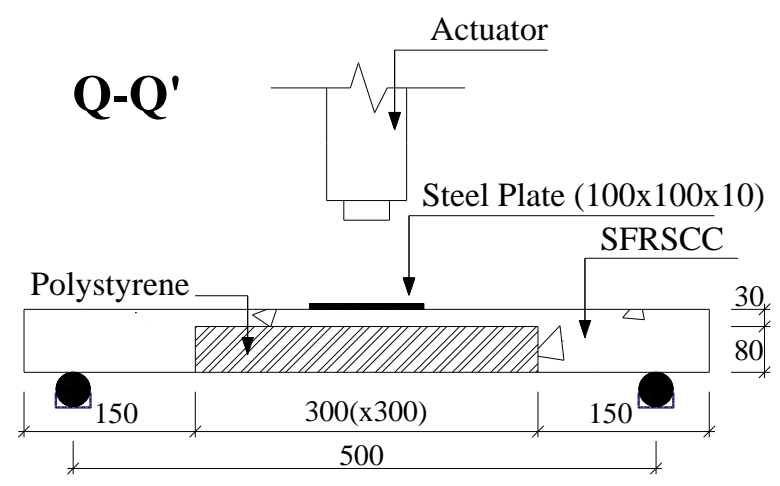

(a) of-plane shear components was capable of fitting with high accuracy the force-deflection response of SFRSCC panels failing in punching, while a much large load carrying capacity was predicted assuming a linearelastic response.

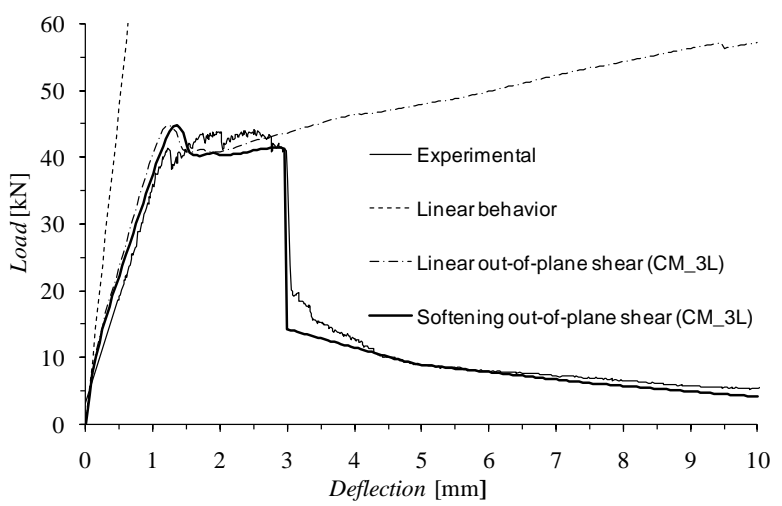

(b)

Figure 10: (a) Test setup of a SFRSCC panel submitted to punching; (b) load-deflection at the center of the panel [32].

This modelling strategy was applied for slabs flexurally reinforced with conventional steel bars, and shear reinforced with steel fibers, by investigating the influence of the strength class of SFRSCC and the content of steel fibers [33]. Figure 11 evidences that this strategy is adequate for capturing the deformational and

(a)
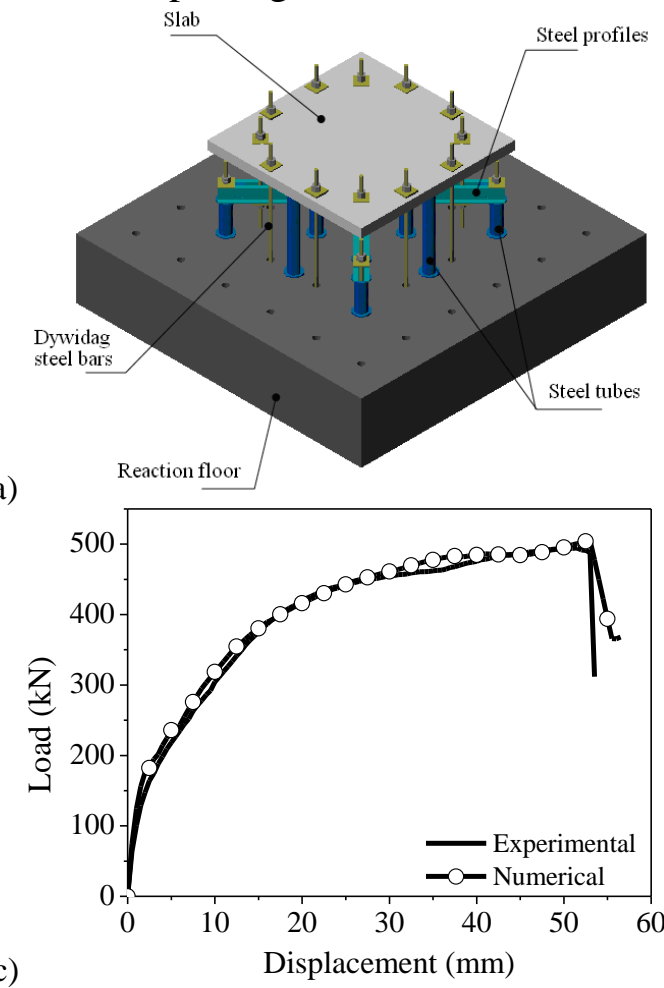

load carrying capacity of this type of structures, but no experimental setup still exist for a direct evaluation of the properties that define the outof-plane shear stress vs shear strain diagram, so specific research in this topic is required. the out-of-plane shear fracture energy.

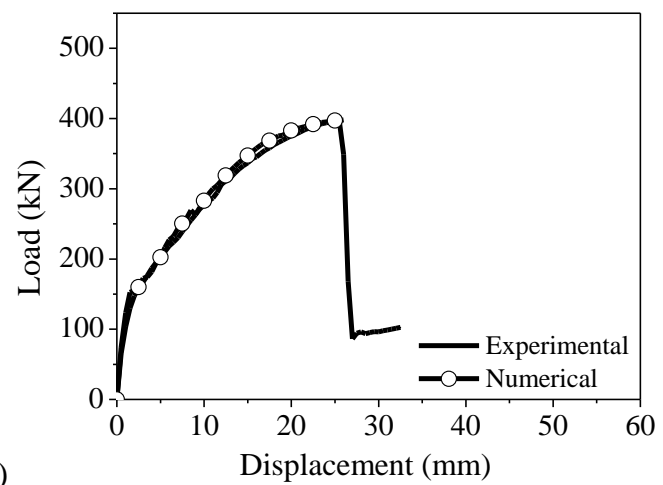

(b)

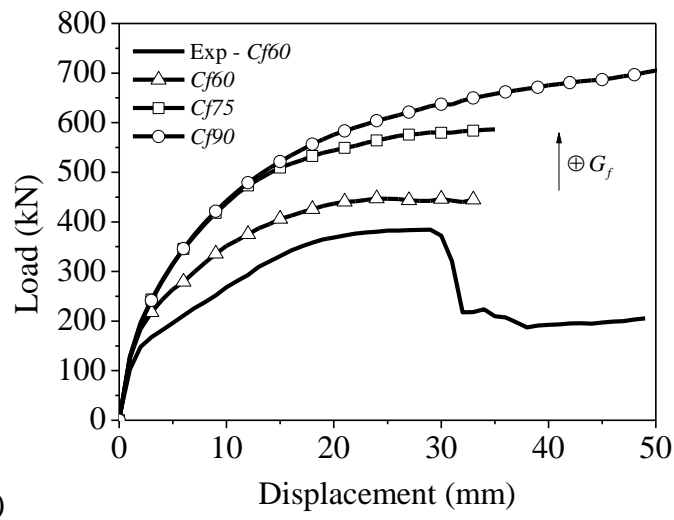

Figure 11: Punching shear tests with SFRSCC slabs: (a) Test setup; (b) and (c) Experimental and numerical results for the series of SFRSCC slabs of $70 \mathrm{MPa}$ strength class without fibers and reinforced with $90 \mathrm{~kg} / \mathrm{m}^{3}$ of steel fibers, respectively; (d) influence of the out-of-plane fracture energy [33]. 
In fact, Figure 11d demonstrates that the deformational and the load carrying capacity of this type of slabs increase with

\subsection{Strategies for assuring mesh objectivity in the simulation of the fracture process}

Due to the smeared crack nature of the models that are being discussed, a concept of crack normal tensile strain $\left(\varepsilon_{n}^{c r}\right)$ is used to describe the tensile deformation process occurred in this type of materials, but the fracture model parameters are obtained by measuring the opening of a single crack, $w$, and determining the area under the obtained $\sigma-\mathrm{W}$ relationship. To transform the crack width in a crack strain, the concept of crack bandwidth, $l_{b}$, is used ( $\left.\varepsilon_{n}^{c r}=w / l_{b}\right)$, which is made dependent of a certain length entity of the finite element where crack is formed and progressing, in order to assure the results of the simulation are independent of the finite mesh refinement. Some simple strategies were proposed [22,34], where $l_{b}$ is dependent of the type of finite element, integration scheme, and type of expected failure mode (flexure, shear, or mixed flexural-shear). More refined approaches attribute to each crack its own crack band width, being $l_{b}$ the maximum length orthogonal to the crack plane, possible to inscribe in the area/volume (2D or 3D continuous finite elements) of the material representative of the SP [6]. More sophisticated approaches have been proposed, where a function is considered to simulate the displacement field discontinuity when a crack is formed [35], or via strain-softening constitutive equations [36]. Embedded discontinuity formulations have conceptually similar purpose [37], and one of this refined formulations was extended in order to cover situations where failure is governed, not only by fracture mode I, but also by fracture mode II [38].

A simple approach assuming $l_{b}=\sqrt{A_{S P}}$ for $2 \mathrm{D}$ finite elements, where $A_{S P}$ is the area of the cracked SP, and $l_{b}=\sqrt[3]{V_{S P}}$ for $3 \mathrm{D}$ finite elements, where $V_{S P}$ is the volume of the cracked sampling point, seems a good compromise in terms of preserving results independent of the finite element refinement and computational demands when relatively large size structures are analyzed.

For the crack shear softening diagram (Figure 7) previously indicated for modeling the crack shear stress transfer during the fracture process evolution, the crack band width adopted for fracture mode I is also considered for the fracture mode II (and even for mode III in case of solid finite elements), but further research in this respect is required. To assure results independent of the mesh refinement in problems failing in shear or in torsion (governed by fracture mode II and III) it is fundamental to adopt a crack shear softening approach where the fracture energy mode II and III is dissipated in a crack band width associated to a length characteristic of the cracked integration point. By adopting the shear retention factor for modeling the degradation of crack shear stress transfer, the results are dependent of the finite element refinement in this type of problems.

\subsection{Simulation of cracked concrete transversely submitted to inelastic deformation in compression}

To couple the inelastic behavior of cement based materials in compression with the nonlinearities caused by crack formation and propagation, the MSCM can be coupled with a formulation that combines plasticity and damage theories [39]. This plastic-damage multidirectional fixed smeared crack (PDSC) model is formulated in effective (undamaged) stress space and adopts a single hardening parameter to account for the compressive plastic deformations. The plasticity approach is combined with an isotropic damage model to account for strength and stiffness degradation of the material under compression. For cement based materials submitted to compression, fiber reinforcement has only an appreciable contribution in the post-peak stage (stage III in Figure 12a). In fact, the area under the stressstrain relationship ( $G_{f, c}-$ compressive fracture energy) increases with the content of fibers [3]. Therefore, by tailoring the function that defines 
the compressive damage scalar, $d_{c}$, which is function of the inelastic compressive deformation, the influence of fiber reinforcement can be simulated. However, experimental research on the characterization of the post-peak compression response of cement based materials evidences this stage is dependent of the test setup, stiffness of the equipment, monitoring conditions to control the test and to measure the axial strain, the geometry of the specimen and the interface conditions between specimen and loading platens of the equipment [40].

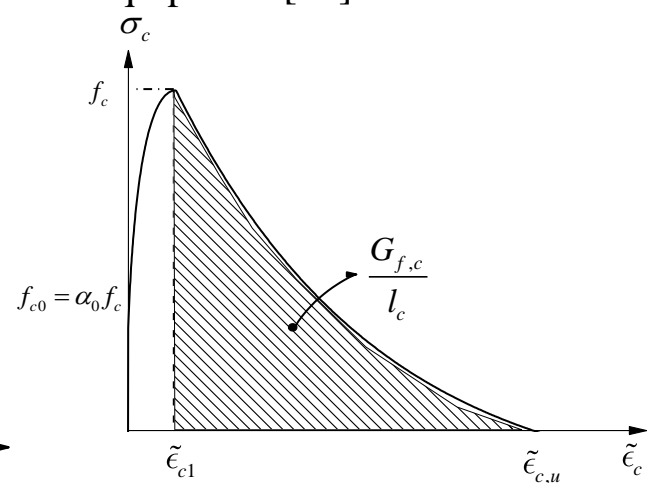

(c) (a)

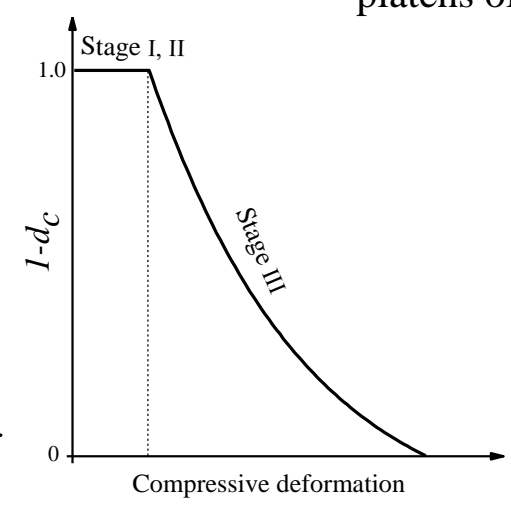

(b)

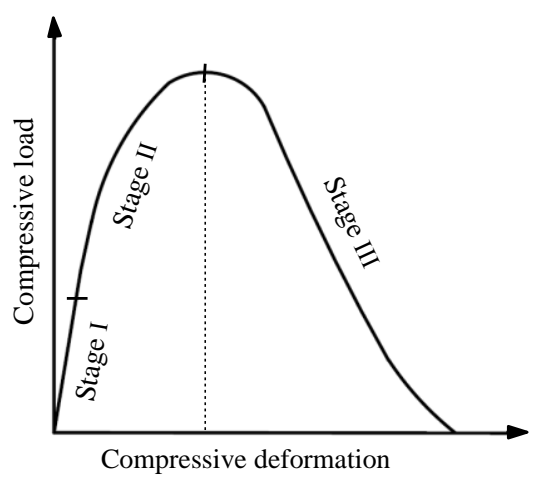

Figure 12: Behavior of the cement based materials under uniaxial compression: (a) three stage of cracking; (b) schematic representation of damage evolution; (c) $\sigma_{c}-\tilde{\epsilon}_{c}$ diagram for compression with indication of the compressive fracture energy, $G_{f, c}[39]$.
Therefore the characterization of this parameter is involved in these aspects, requiring further clarifications, since the numerical simulations of structures with relatively large volume of concrete developing inelastic compressive

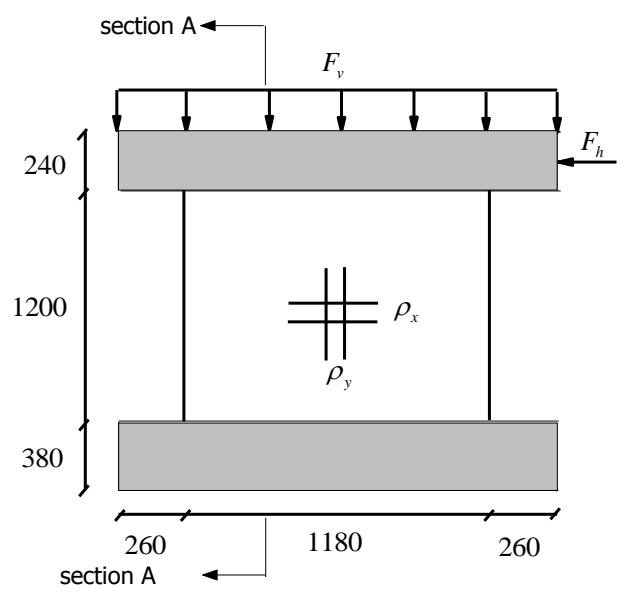

(a)

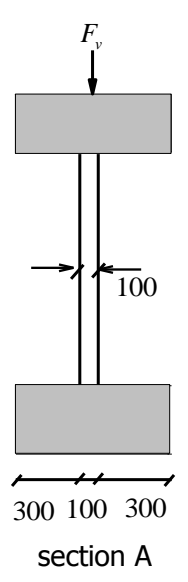

section $A$ deformation, such is the case of the one represented in Figure 13, show that the maximum load carrying capacity and deformability performance increase with $G_{f, c}$.

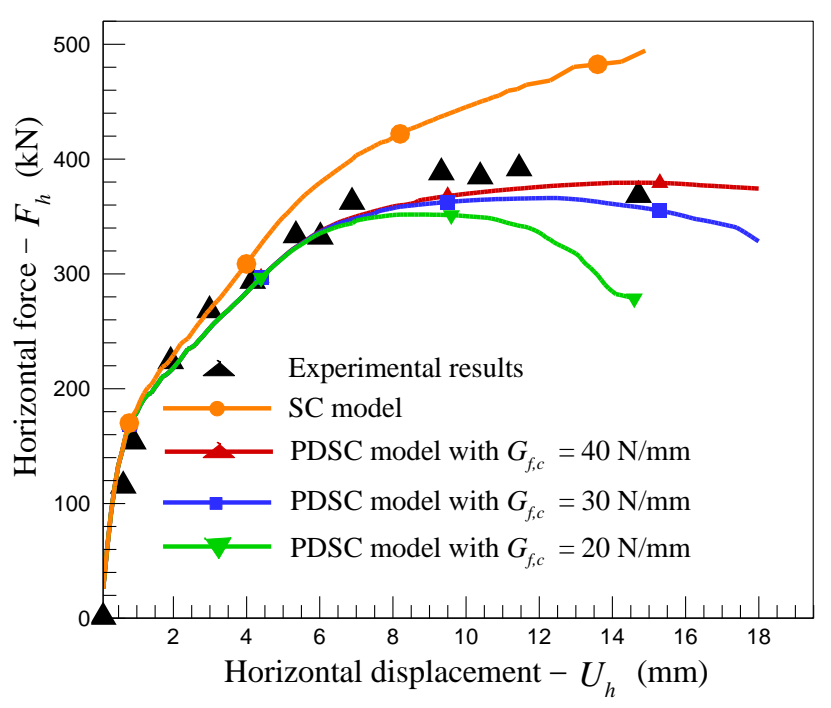

(b)

Figure 13: Simulation of the S4 shear wall tested by Maier and Thürlimann [40]: (a) geometry and loading configurations (dimensions in $\mathrm{mm}$ ); (b) horizontal load versus horizontal displacement diagram, Fh-Uh [39].

\section{CONCLUSIONS}

An overview of the potentialities and debilities of smeared crack models for the analysis of fiber reinforced cement composites (FRCC) was made, by considering the computational aspects, the influence of the model parameters on the predictive performance of these approaches, and the difficulties that still exist 
on the experimental assessment of the values of these parameters. The final aim is to recommend fields of research for improving the reliability of the numerical simulations with these models. Based on this overview, the following observations can be pointed out:

1. Multidirectional fixed smeared crack models (MSCMs) are capable of simulating FRCC structures failing in bending, provided that the fracture parameters are properly determined. For this purposes, double edge wedge splitting test with specimens extracted from FRCC volume representative of the real application conditions seems the best strategy. For capturing the influence of fiber distribution and orientation, the fracture parameters should depend of the crack orientation.

2. For modeling the behavior of FRCC failing in shear and punching, a crack shear stressshear strain diagram capable of simulating the shear stress transfer degradation with the evolution of the fracture process is fundamental, not only for predicting with enough accuracy the load carrying capacity and deformation performance, but also the crack patterns. However, the determination of the fracture modes II and III parameters requires specific experimental research.

3. MSCMs can be coupled with plastic damage models to simulate the nonlinear behavior of FRCC structures subjected to different loading paths, since the compressive damage scalar can simulate the relevant effects of fiber reinforcement in compression. However, the characterization of this damage parameter is dependent of the experimental test setup conditions adopted.

\section{ACKNOWLEDGEMENTS}

The author acknowledges the support provided by SUPERCONCRETE Marie SklodowskaCurie Actions, Research and Innovation Staff Exchange (RISE), proposal 645704.

\section{REFERENCES}

[1] Laranjeira, F. 2010. Design-oriented constitutive model for steel fiber reinforced concrete. $\mathrm{PhD}$ thesis, Universitat
Politècnica de Catalunya.

[2] Abrishambaf, A., Barros, J.A.O., Cunha, V.M.C.F. 2013. Relation between fibre distribution and post-cracking behaviour in steel fibre reinforced self-compacting concrete panels. Cement \& Concrete Research, 51, 57-66.

[3] Bentur, A., Mindess, S. 2007. Fibre Reinforced Cementitious Composites. 2nd edition, Francis \& Taylor, UK.

[4] Rossi, P. 1998. Steel fibre reinforced concrete. Ed. Lavoisier, 309 pages, EAN13: 9782859782924. (in French).

[5] Azevedo, A.F.M.; Barros, J.A.O. 1990. A comparative analysis of direct and iterative methods for the resolution of big systems of linear equations. 2nd Portuguese Meeting of Structural Engineering, LNEC, Lisboa, Theme A, p. A91-A102.

[6] Dahlblom, O., Ottosen, N.S. 1990. Smeared crack analysis using generalized fictitious crack model. Jour. of Eng. Mech., ASCE, 116(1), 55-76.

[7] de Borst, R. 1987. Smeared cracking, plasticity, creep and thermal loading - a unified approach. Comp. Meth. Appl. Mech. Eng., 62, 89-110.

[8] Willam, K., Pramono E., Sture, S. 1987. Fundamental issues of smeared crack models. SEM/RILEM Inter. Conf. on Fracture of Concrete and Rock, Houston, Texas, edited by S.P. Shah and S.E. Swartz, pp. 142-157.

[9] van Mier, J.G.M. 1997. Fracture processes of concrete: assessment of material parameters for fracture models. New directions in civil engineering, CRC Press.

[10]Bencardino, F., Rizzuti, L., Spadea, G., Swamy, R.N. 2010. Experimental evaluation of fibre reinforced concrete fracture properties. Compos. Part B. 41, 17-24.

[11]Cunha, V.M.C.F. 2010. Steel fibre reinforced self-compacting concrete-from micromechanics to composite behaviour. Civil Engineering Department, University of Minho, Portugal.

[12]Ferrara, L., Meda, A. 2012. Relationships between fibre distribution, workability and the mechanical properties of SFRC applied 
to precast roof elements. Mater. Struct. 39, 411-420.

[13] Abrishambaf, A., Barros, J.A.O., Cunha, V.M.C.F. 2015. Tensile stress - crack opening law for steel fibre reinforced selfcompacting concrete obtained from indirect (splitting) tensile tests. Cement and Concrete Composites, 57, 153-165.

[14] Carmona, S., Aguado, A. 2012. New model for the indirect determination of the tensile stress-strain curve of concrete by means of the Brazilian test. Mater. struct. 45, 14731485.

[15]Pereira, E.B., Barros, J.A.O., Camões, A.F.F.L. 2008. Steel fiber reinforced selfcompacting concrete - experimental research and numerical simulation. ASCE Struct. Engng Journal, 134(8), 1310-1321.

[16] Sena-Cruz, J.M., Barros, J.A.O., Ribeiro, A.F., Azevedo, A.F.M., Camões, A.F.F.L. 2004. Stress-crack opening relationship of enhanced performance concrete. 9th Portuguese Conference on Fracture, ESTSetúbal, Portugal, p. 395-403.

[17] CEB-FIP. 2012. Vol. 1, Model Code 2010, Tomas Telford, Lausanne, Switzerland.

[18] Prisco, M., Ferrara, L., Lamperti, M.G.L. 2013. Double edge wedge splitting (DEWS): an indirect tension test to identify post-cracking behaviour of fibre reinforced cementitious composites. Mater. Struct. 46, 1893-1918.

[19] Salehian, H., Barros, J.A.O. 2015. Assessment of the performance of steel fibre reinforced self-compacting concrete in elevated slabs. Cement and Concrete Composites, 55, 268-280.

[20]Barros, J.A.O., Pereira, E.N.B., Gouveia, A.V., Azevedo, A.F.M. 2007. Numerical simulation of thin steel fiber selfcompacting concrete structures. ACI SP248 Deflection and stiffness Issues in FRC Thin Structural Elements, Eds: P. Bischoff and F. Malhas, paper SP-248-1, 1-16.

[21] Cunha, V.M.C.F., Barros, J.A.O., SenaCruz, J.M. 2012. A finite element model with discrete embedded elements for fibre reinforced composites. Computers and Structures Journal, 94-95, 22-33.

[22]Rots, J.G. 1988. Computational modeling of concrete fracture. $\mathrm{PhD}$ thesis, Delft University of Technology.

[23] Barros, J.A.O. 1995. Behaviour of fibre reinforced concrete - experimental research and numerical simulation", $\mathrm{PhD}$ Thesis, Civil Eng. Dept., F.E. University of Porto, (in Portuguese).

[24] Divakar, M.P., Fafitis, A., Shah, S.P. 1987. A Constitutive Model for Shear Transfer in Cracked Concrete. J. Structural Div., ASCE, 113(5), 1046-1062.

[25] Nooru, M.B.-Mohamed. 1992. Mixedmode fracture of concrete: an experimental approach. PhD thesis, Delft University of Technology.

[26]Barros, J.A.O., Baghi, H., Dias, S.J.E., Ventura-Gouveia, A. 2013. A FEM-based model to predict the behaviour of $\mathrm{RC}$ beams shear strengthened according to the NSM technique. Engineering Structures Journal, 56, 1192-1206.

[27] Sena-Cruz, J.M. 2004. Strengthening of concrete structures with near-surface mounted CFRP laminate strips. PhD Thesis, Dep. Civil Engng, Univ. Minho.

[28] Ventura-Gouveia, A. 2011. Constitutive models for the material nonlinear analysis of concrete structures including time dependent effects. PhD Thesis, Dep. Civil Engng, Univ. Minho.

[29]Barros, J.A.O., Costa, I. G., VenturaGouveia, A. 2011. CFRP flexural and shear strengthening technique for RC beams: experimental and numerical research. Adva. in Struct. Engng J., 14(3), 559-581.

[30] Soltanzadeh, F., Barros, J.A.O., Santos, R.F.C. 2015. High performance fiber reinforced concrete for the shear reinforcement: experimental and numerical research. J. Construction and Building Materials, 77, 94-109.

[31]Zamanzadeh, Z., Lourenço, L.A.P., Barros, J.A.O. 2015. Recycled steel fibre reinforced concrete failing in bending and in shear. J. Construction and Building Materials, 85, 195-207.

[32] Ventura-Gouveia, A., Barros, J.A.O., Azevedo, A.F.M. 2011. Crack constitutive model for the prediction of punching failure modes of fiber reinforced concrete 
laminar structures. Computers \& Concrete, Zürich. 8(6), 735-755.

[33] Teixeira, M.D.E., Barros, J.A.O., Cunha, V.M.C.F., Moraes-Neto, B.N., VenturaGouveia, A. 2015. Numerical simulation of the punching shear behaviour of selfcompacting fibre reinforced flat slabs. J. Construction and Building Materials, 74, 25-36.

[34]Rots, J.G., Nauta, P., Kusters, G.M.A., Blaauwendraad, J. 1985. Smeared crack approach and fracture localization in concrete", HERON, Vol. 30, $\mathrm{N}^{\mathrm{o}} 1$.

[35] Oliver, J. 1990. Modeling the cracking process in concrete structures. Centro de Métodos Numéricos en Ingenieria, Barcelona, 99 pp. (in Spanish).

[36a] Oliver, J. 1996. Modelling strong discontinuities in solid mechanics via strain softening constitutive equations. Part 1: fundamentals. Int. J. Numer. Methods Engrg. 39 (21), 3575-3600.

[36b] Oliver, J. 1996. Modelling strong discontinuities in solid mechanics via strain softening constitutive equations. Part 2: numerical simulation. Int. J. Numer. Methods Engrg. 39 (21), 3601-3623.

[37]Jirásek, M., Zimmermann, T. 2001. Embedded crack model: I. Basic formulation. Int. J. Numer. Meth. Engng, 50, 1269-1290.

[38]Dias-da-Costa, D., Alfaiate, J., Sluys, L.J., Júlio, E. 2009. Towards a generalization of a discrete strong discontinuity approach. Comput. Methods Appl. Mech. Engrg, 198, 3670-3681.

[39]Behbahani, A.E., Barros, J.A.O., VenturaGouveia, A. 2015. Plastic-damage smeared crack model to simulate the behaviour of structures made by cement based materials", Int. J. Solid Structures, 73-74, 20-40.

[40] Van Mier, J.G.M. 1984. Strain-softening of concrete under multiaxial loading conditions", PhD Thesis, Delft University of Technology.

[41]Maier, J. and Thürlimann, B. 1985. Bruchversuche an Stahlbetonscheiben", IBK Bericht 8003-1, ETH Zürich, Institut für Baustatik und Konstruktion (IBK), 